\title{
Stigmatiziraju li studenti i studentice sestrinstva oboljele od posttraumatskog stresnog poremećaja?
}

1 Josipa Rožman

1 Goran Arbanas

1 Opća bolnica Karlovac, Odjel psihijatrije, Andrije Štampara 3, 47000 Karlovac

\section{Sažetak}

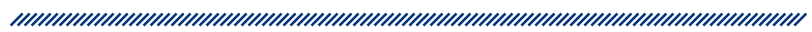

Psihijatrijski bolesnici, osim poteškoća povezanih sa svojim primarnim oboljenjem, suočeni su i s poteškoćama koje proizlaze iz njihove stigmatizacije u sredini u kojoj žive. Diskriminirajuća ponašanja poput ograničavanja zdravstvene skrbi ili prava na obrazovanje i različitih situacija povezanih sa zapošljavanjem samo su neki od primjera koji mogu dodatno ugroziti i fizičko i psihičko zdravlje stigmatiziranih osoba. Stigmatizacija dovodi do sniženja samopoštovanja te do osjećaja izolacije, usamljenosti i diskriminacije, što dodatno otežava liječenje primarne bolesti.

Stigma je čest pratitelj psihičkih bolesti koji ometa liječenje i funkcioniranje. U Republici Hrvatskoj nakon Domovinskog rata postoji velik broj oboljelih od posttraumatskog stresnog poremećaja (PTSP), koji se u medijima često prikazuju na negativan način.

Ovo je istraživanje provedeno na 94 studenta i studentica sestrinstva. Žena je bilo $85 \%$, prosječne dobi od 32 godine (raspon od 22 do 54). Stigma prema shizofreniji, depresiji i PTSP-u ispitivana je upitnikom koji se sastoji od po 15 izjava o svakoj od bolesti, koje se ocjenjuju po Likertovoj ljestvici.

\begin{abstract}
Studenti su pokazivali značajno veću stigmu prema shizofreniji nego prema PTSP-u i depresiji. Žene su bile više stigmatizirajuće prema shizofreniji. Studenti prve godine više su stigmatizirajući prema PTSP-u od studenata druge i treće godine. Stariji studenti (od 36 godina) bili su više stigmatizirajući od mlađih.
\end{abstract}

Ključne riječi: stigma, shizofrenija, depresija, PTSP, studenti sestrinstva

Datum primitka: 19.07.2015.

Datum prihvaćanja: 08.09.2015.

\section{Adresa za dopisivanje:}

Josipa Rožman, bacc.med.tehn.

Opća bolnica Karlovac

Andrije Štampara 3, Karlovac

Tel.: 0958019871

E-pošta: josipa.rozman@bolnica-karlovac.hr

\section{Uvod}

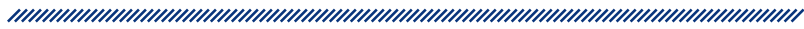

Svjetska zdravstvena organizacija (SZO) definirala je mentalno zdravlje kao stanje dobrobiti u kojem pojedinac ostvaruje svoje potencijale, može se nositi s normalnim životnim stresom, može raditi produktivno i plodno te je sposoban pridonositi zajednici. Tijekom povijesti, sve do danas, psihičke su bolesti bile praćene socijalnim odbacivanjem, strahom i stigmom ${ }^{1}$. Sti- 
gmatiziranje osoba oboljelih od psihičkog poremećaja temelji se na predrasudama te nastaje na temelju nedovoljnog znanja o psihičkim bolestima. Riječ stigma imenica je grčkog podrijetla koja dolazi od korijena čije je značenje „naglasiti, istaknuti, označiti“. Ova je riječ preuzeta metaforički i predstavlja oznaku srama ili degradacije ${ }^{2}$.

U Hrvatskoj je nakon Domovinskog rata više od 7500 ljudi zbog obolijevanja od posttraumatskog stresnog poremećaja (PTSP) ostvarilo status hrvatskoga ratnog vojnog invalida. Tijekom proteklih dvadeset godina, nakon početne podrške i pozitivnog stava prema braniteljima, u medijima dolazi do sve negativnijeg prikaza branitelja i oboljelih od PTSP-a. Frančišković, Stevanović, Blažić i sur. ${ }^{3}$ pokazali su da se prikaz oboljelih od PTSP-a u dnevnim i tjednim novinama mijenjao te da se tijekom razdoblja od deset godina povećao broj članaka koji prikazuju negativne aspekte PTSP-a (npr. crna kronika, suicidi), a smanjio se broj članaka (čak tri puta) koji prikazuju pozitivne aspekte (npr. godišnjice, sjećanja). Poznato je da mediji pridonose stigmatizaciji psihičkih bolesti, prikazujući ih kao nepredvidljive, nasilne i opasne, a u filmovima se psihičke bolesnike znalo prikazivati kao ubojice ${ }^{2,3}$. Čak $72 \%$ psihički bolesnih likova iz TV drama portretirano je kao nasilno, a sve veći broj popularnih filmova koji povezuju psihički poremećaj s nasiljem (Psiho, Petak 13., Kad jaganjci utihnu, Sedam, Isijavanje itd.) samo govori u prilog raširenosti stereotipa koji je prisutan i danas 4 .

Primjeri su ovakvog senzacionalističkog i stigmatizirajućeg pristupa prema oboljelima od PTSP-a u dnevnim medijima: „47-godišnji umirovljeni vojnik, koji iz ratnog razdoblja vuče PTSP, zatvorio se u svoju kuću u Crnom Selu te je prijetio da će pobiti sve koji mu se približe“ (http://www.rtl.hr/vijesti/novosti/15769/ptsp-ovacprijetio-da-ce-pobiti-sve/ pristupljeno 2. lipnja 2014); „PTSP-ovac zatočio službenike Mirovinskog“ (http:// www.jutarnji.hr/ptsp-ovac-zatocio-sluzbenike-mirovinskog/271267/ pristupljeno 2. lipnja 2014.); „Rastrojeni hrvatski branitelj popeo se na krov svoje kuće te je s kanistrom punim benzina dva sata prijetio da će zapaliti i sebe i kuću u kojoj mu je bila obitelj“ (http://www.rtl. hr/vijesti/novosti/3738/na-krovu-prijetio-samozapaljenjem/ pristupljeno 2. lipnja 2014.). Takvim pisanjem mediji pretvaraju incidentnu situaciju u stigmu prema svim oboljelima te na taj način povećavaju ionako stigmatizirajuće mišljenje javnosti o psihičkim bolesnicima. Osobe oboljele od PTSP-a dojma su da su slabo prihvaćeni od opće populacije, čemu svakako pridonosi i ovakav prikaz bolesti u novinskim izvješćima. Brojna istraživanja provedena na ovom polju pokazuju da ispitanici najčešće percipiraju osobe sa shizofrenijom kao nepredvidljive i opasne ${ }^{5}$. Psihičke bolesnike stigmatiziraju ne samo laici nego i zdravstveni djelatnici. Filipčić i sur. pokazali su prisutnost predrasuda i stigmatizirajućih stavova kod liječnika, medicinskih sestara i tehničara te studenata medicinskog fakulteta ${ }^{6}$. Lai i sur. u istraživanju na uzorku od 300 psihički oboljelih osoba, 100 zdravstvenih djelatnika i 50 osoba oboljelih od kardiovaskularnih bolesti također su dokazali kako je razina stigme prema psihički oboljelim osobama velika te su ukazali na važnost povećavanja javne svijesti o psihičkim bolestima ${ }^{7}$ I same osobe oboljele od psihičkih bolesti imaju stigmatizirajuće stavove prema tim istim psihičkim bolestima ${ }^{8}$, kao i članovi obitelji oboljelih od psihičkih bolesti ${ }^{9}$. Pri tome se osobe sa psihičkim bolestima najčešće doživljavaju kao opasne i nasilne te nesposobne za samostalan život, donošenje odluka, za život i privređivanje. Istraživanje koje je proveo Wahl na uzorku od 100 psihički oboljelih osoba pokazalo je njihovo iskustvo stigme iz raznih izvora, uključujući društvene i poslovne zajednice, obitelj i crkvu. Većina ispitanika prikrivala je svoje bolesti i pokazala veliku razinu zabrinutosti zbog mogućnosti otkrivanja njihovih bolesti ponajviše radi reakcija okoline ${ }^{10}$.

Usporedba stigmatizacije psihički oboljelih osoba u periodu od 1950. do 1996. g. pokazala je kako je percepcija o psihičkim bolesnicima kao nasilnima i zastrašujućima porasla, što je bilo iznenađujuće jer je očekivano da će u razdoblju velikog napretka medicine napredovati i svijest opće populacije o psihički oboljelim osobama u pozitivnom smislu ${ }^{11}$. Zbog stigme se oboljeli ne koriste uslugama službi za zaštitu psihičkog zdravlja, slabije se pridržavaju liječenja i umanjena im je mogućnost zapošljavanja ${ }^{12}$. Učinak stigme može biti teži i dugotrajniji nego učinak same psihičke bolesti. Psihijatrijski bolesnici, osim poteškoća povezanih s njihovim primarnim oboljenjem, suočeni su i s poteškoćama koje proizlaze iz njihove stigmatizacije u sredini u kojoj žive. Rezultati istraživanja koje su proveli Jokić Begić i sur. 2005. godine ukazali su na široko prihvaćen negativan stereotip o psihičkim bolesnicima. lako stavovi prema njima variraju od neutralnih do pozitivnih, prihvaćanje psihičkih bolesnika je znatno slabije: više od $50 \%$ sudionika pokazalo je veću socijalnu distancu prema njima. Rezultati su također pokazali da što više ljudi znaju o psihičkim bolesnicima, to su pozitivniji njihovi stavovi prema njima i veći je stupanj prihvaćanja takvih osoba ${ }^{13}$. Unatoč tome, dosadašnja istraživanja u Hrvatskoj pokazala su da je stav mladih ljudi u Hrvatskoj prema PTSP-u manje 
obojen stigmom nego stav prema shizofreniji ${ }^{14}$. Nažalost, istraživanja stigme prema PTSP-u malobrojna su i u svjetskim razmjerima. S obzirom na to da se oboljeli od PTSP-a često koriste zdravstvenim uslugama, ne samo u području psihičkog zdravlja nego i u području „organske" medicine (a zbog činjenice da oboljeli od PTSP-a imaju povišene stope kardiovaskularnih, endokrinoloških, gastrointestinalnih i niza drugih bolesti), željelo se vidjeti kakav je stav studenata sestrinstva prema oboljelima od ovog poremećaja. Studenti sestrinstva osobe su koje imaju specifična znanja, ali i ranije iskustvo u radu s bolesnicima te su vjerojatno dolazili u doticaj i s oboljelima od PTSP-a. Zbog brojnih dosada provedenih istraživanja stigme prema shizofreniji i depresiji, upravo su ove dvije bolesti odabrane kao usporedba u odnosu na PTSP.

\section{Metoda}

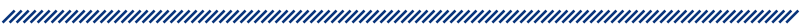

\section{Sudionici}

Istraživanje je provedeno na uzorku od 129 izvanrednih studenata prve, druge i treće godine Stručnog studija sestrinstva u Karlovcu, dislocirani studij Medicinskog fakulteta Rijeka. Svi su studenti zaposleni kao medicinske sestre/tehničari.

Upitnik je osobno ponuđen svim studentima, ispunjavali su ga za vrijeme nastave i njih 110 pristalo je sudjelovati u istraživanju, što čini $85 \%$ ukupnog broja. Odaziv je po godinama studija bio nejednak, što se vidi u tablici $1\left(\chi^{2}=33,4 ; p<0,001\right)$. Neki upitnici nisu bili u potpunosti ispunjeni, tako da smo na kraju imali uzorak od 94 studenta.

Žena je bilo $85 \%$, što odgovara rodnom omjeru na studiju. Muških je ispitanika bilo devet na trećoj godini, pet na drugoj te nijedan na prvoj godini studija $\left(\chi^{2}=6,53\right.$; $p=0,038)$. Ovakva razlika odgovara izvornoj populaciji (jedan muškarac na prvoj godini, sedam na drugoj i deset na trećoj).

Dob ispitanika bila je u rasponu od 22 do 54 godine, prosječna dob 32,0 godina i medijan 33 godine. Ispitanici prve godine mlađi su od studenata druge i treće godine $(t=3,278 ; p=0,001)$ (tablica 2). Nije bilo razlike $u$ dobi po spolu.

\section{Instrument}

Za mjerenje stigme primijenjen je upitnik kojim je već u ranijim istraživanjima utvrđivana stigma prema psihičkim bolestima (Arbanas 2005) ${ }^{15}$. Ovaj upitnik sadrži 15 izjava na temelju kojih su ispitanici ocjenjivali svoj stav prema psihičkoj bolesti (npr. „Mislim da osobe oboljele od PTSP-a ne mogu dobro obavljati svoj posao.“ ili „Da iznajmljujem stan, vjerojatno ga ne bih iznajmio osobi oboljeloj od PTSP-a.“). Uz svaku od izjava ocjenjivao se stav po Likertovoj ljestvici, tj. 0 - potpuno se slažem, 1 - slažem se, 2 - niti se slažem, niti se ne slažem, 3 - ne slažem se i 4 - uopće se ne slažem. Za izračunavanje stigmatizacije zbrojene su vrijednosti pojedinih čestica (tj. inverzne vrijednosti, $4-x$, u slučaju čestica slaganje $s$ kojima se ukazuje na manju stigmu - kao što su čestice u primjeru).

Da bi se usporedila stigma prema depresiji i shizofreniji, uz čestice koje opisuju odnos prema oboljelima od PTSP-a dodane su istovjetne čestice za depresiju i shizofreniju. Na ovakav je način ukupno dobiveno 45 čestica. $\mathrm{U}$ upitniku su bile navedene slučajnim redoslijedom.

\begin{tabular}{|c|c|c|c|}
\hline \multicolumn{4}{|c|}{ Tablica 1. Odaziv studenata sestrinstva (po godinama studija) } \\
na ispitivanje stigme prema psihičkim bolestima
\end{tabular}

\begin{tabular}{|c|c|c|c|}
\hline \multicolumn{4}{|c|}{ Tablica 2. Dob ispitanika po godinama studija } \\
\hline & godina & godina & godina \\
\hline Dob ispitanika $(g)$ & $28,71 \pm 5,26$ & $34,00 \pm 6,65$ & $32,37 \pm 4,98$ \\
\hline
\end{tabular}


Upitnik je bio anoniman, a ispunjavanje dobrovoljno. Od demografskih se podataka od ispitanika tražilo da navedu svoj spol, dob i godinu studija.

\section{Rezultati}

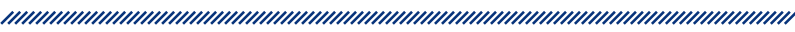

Na slici 1 prikazani su rezultati istraživanja povezani sa stigmatizacijom po spolu i po dijagnozama. Jasno se vidi da je i kod žena i kod muškaraca stigma prema shizofreniji značajno veća nego stigma prema depresiji i PTSP-u $(p<0,001)$. S druge strane, nije bilo razlike između stigme prema depresiji i PTSP-u. Muškarci i žene nisu se razlikovali po stigmi prema depresiji i PTSP-u, no žene su bile više stigmatizirajuće prema oboljelima od shizofrenije $(p=0,036)$.

Nije bilo razlike u stigmatizaciji prema godini studija, uz izuzetak da su studenti prve godine više stigmatizirali osobe s PTSP-om nego studenti druge i treće godine $(\mathrm{t}=$ 2,194; $p=0,033$ ) (slika 2).

Ispitanici stariji od 36 godina imali su više stigmatizirajuće stavove prema shizofrenim ( $p<0,001)$ i depresivnim osobama $(p=0,044)$, dok je za PTSP postojala samo tendencija tome $(p=0,076)$ (slika 3).

\section{Rasprava}

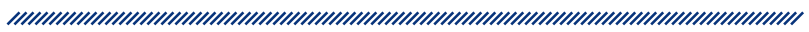

Medicinske sestre i tehničari doživljavaju se među ljudima kao oni koji su u zdravstvu u vrhu po pitanju etičnosti $\mathrm{i}$ iskrenosti ${ }^{16}$. Oni su prvi u kontaktu s bolesnikom i imaju važnu ulogu u mjerama postupanja prema osobama oboljelima od psihičkih bolesti. Tijekom njihove edukacije i školovanja moguće je djelovanje na znanja i stavove pa time i na stigmatizaciju prema psihičkim bolestima ${ }^{17}$.

Među našim studentima sestrinstva odaziv je bio najveći na trećoj godini studija. Ovo je vjerojatno posljedica činjenice da na trećoj godini slušaju kolegij Psihijatrija, a istraživači sudjeluju u izvođenju ovog kolegija te vjerojatno oni s prve i druge godine nisu bili tako motivirani za sudjelovanje (premda je sudjelovanje bilo anonimno).

Većina su studenata žene (85 \%), što odgovara situaciji u zdravstvu, a posebice sestrinstvu.

Rezultati su pokazali da je stigma prema shizofreniji značajnija i veća od one prema depresiji i PTSP-u. Ovakav je odnos shizofrenije i depresije očekivan, jer većina istraživanja pokazuje da su ljudi (uključujući i zdravstvene djelatnike) negativnijeg stajališta prema shizofreniji nego prema depresiji te da se često boje shizofrenih bolesnika i doživljavaju ih kao opasne. Za razliku od toga, depresivne uglavnom doživljavaju kao one kojima se može pomoći i koji nisu krivi za svoje stanje ${ }^{18}$.

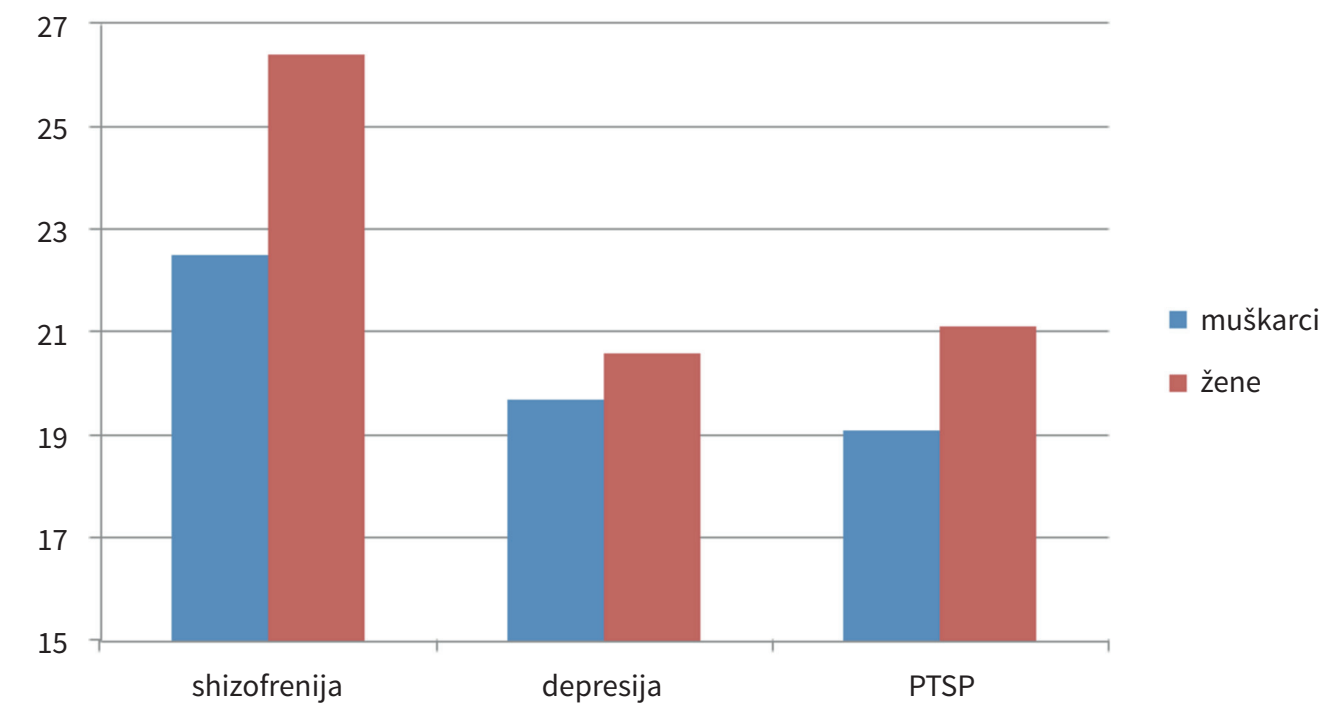


Prema rezultatima naši studenti i studentice nisu pokazali stigmu prema PTSP-u veću od one prema depresiji. Naime, istraživanja medija pokazuju da je stav prema PTSP-u u medijima uglavnom negativan te da se ova bolest prikazuje na senzacionalistički i stigmatizirajući način ${ }^{3}$. Kako vrijeme od Domovinskog rata odmiče, tako se PTSP prikazuje u sve negativnijem kontekstu, s pora- stom broja članaka u crnoj kronici, a smanjenjem u rubrikama o godišnjicama i sjećanjima. Po spolu nije bilo razlike u stigmatizaciji prema depresiji i PTSP-u, a prema shizofreniji su bile više stigmatizirajuće žene. Većina istraživanja pokazuje da su žene manje stigmatizirajuće nego muškarci (u općoj populaciji) ${ }^{6,19}$. Među zdravstvenim se djelatnicima ta razlika smanjuje ${ }^{14}$ vjerojatno

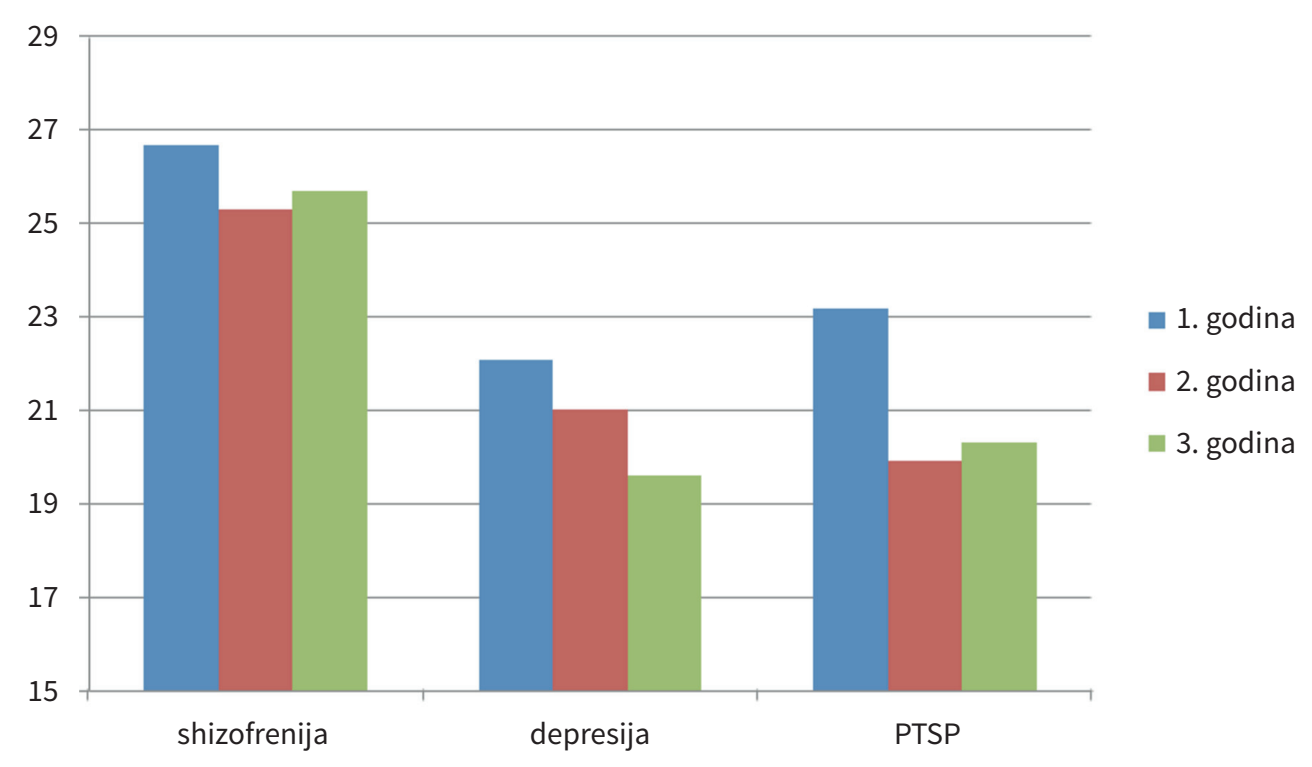

Slika 2. Stigmatiziranje prema psihičkim bolestima, ovisno o godini studija

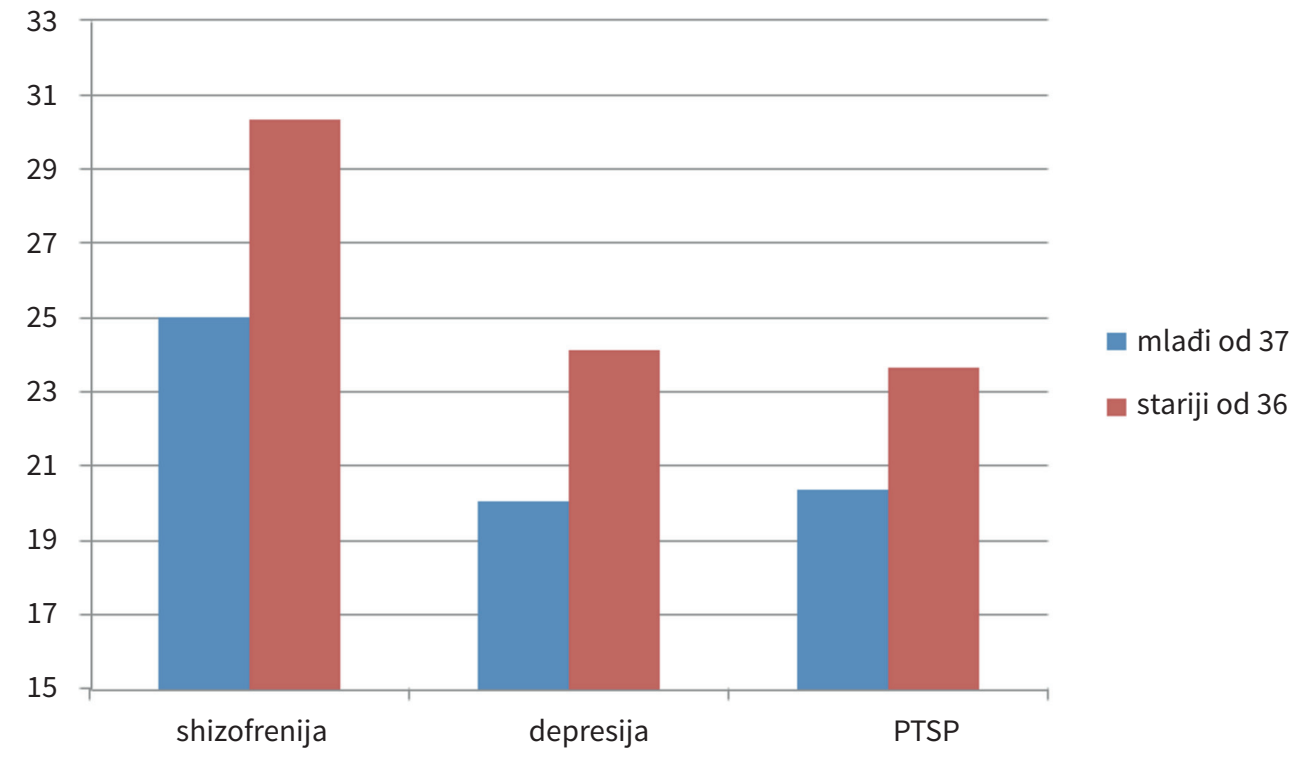


zbog kontakata s bolesnicima i povećanog znanja o psihičkim bolestima, no nismo našli nijedan rad u kojemu su žene pokazivale veću stigmu od muškaraca, tj. u kojem je došlo do inverzije u odnosu na opću populaciju. Moguća objašnjenja mogla bi biti da su u našem uzorku muškarci češće imali nekog člana obitelji oboljelog od shizofrenije ili da su češće radili na psihijatriji i dolazili u kontakt s oboljelima od shizofrenije (na psihijatrijskim odjelima u Hrvatskoj u većini se slučajeva zapošljavaju muškarci), no ovo nismo ispitivali u upitniku.

Po godinama studija nije bilo razlike u stigmatizaciji prema depresiji i shizofreniji, dok su studenti prve godine više stigmatizirali oboljele od PTSP-a u odnosu na one na višim godinama. Očekivali bismo da će studenti na višim godinama (osobito na trećoj, na kojoj se sluša kolegij psihijatrije) biti manje stigmatizirajući. Smatramo da je razlog za odsutnost ovog smanjenja stigme po godinama studija taj što je u konkretnom uzorku riječ o studiju uz rad, tako da svi studenti imaju godine sestrinskog staža i ne razlikuju se po iskustvu. Vjerojatno su svi studenti tijekom svojeg rada dolazili u kontakt s osobama s psihičkim bolestima i sam studij neće značajno pridonijeti kontaktu s ovim bolesnicima, što u drugim uvjetima studiranja može biti važan čimbenik koji utječe na smanjenje stigme (npr. Halter 2004) ${ }^{17}$.

Stariji studenti bili su više stigmatizirajući prema shizofreniji i depresiji nego mlađi. Ovo je u suglasju s nekim drugim istraživanjima koja pokazuju da mlađe osobe i osobe liberalnijih stavova imaju manju stigmatizaciju od starijih i konzervativnijih (Halter 2004) ${ }^{17}$, premda ima i istraživanja koja pokazuju da osobe koje duže rade u zdravstvu (pa su time i starije) imaju manju stigmu. Budući da u našem istraživanju nije bilo velike razlike u dobi između studenata 1., 2. i 3. godine, vjerojatno je ova razlika u stigmi po dobi odraz učinka dobi, a ne godina staža.

Dakle rezultati ovog rada govore u prilog tome da studenti i studentice sestrinstva, unatoč stalno prisutnom negativnom pisanju u dnevnim i tjednim novinama o oboljelima od PTSP-a, nisu preuzeli ovakav stav te ne stigmatiziraju osobe oboljele od PTSP-a ništa više nego oboljele od depresije.

\section{Zaključak}

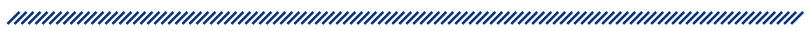

Stigma koja je predstavljena negativnim obilježavanjem osoba samo zato što imaju dijagnozu psihičkog poremećaja danas je veliki društveni, medicinski i etički problem. Usprkos napretku u liječenju osoba s mentalnim poremećajem i pomaku prema liječenju u zajednici, stigma negativno utječe na traženje pomoći, prihvaćanje liječenja, uspješan ishod liječenja, kvalitetu života i integraciju oboljelih u zajednici. Stigma psihičke bolesti vrlo je raširena, ima psihološke, socijalne i ekonomske posljedice za stigmatizirane osobe te narušava ljudska prava oboljelih na poštovanje, ravnopravnost i liječenje. Medicina i psihijatrija kao struka te svi zdravstveni djelatnici moraju razvijati uspješne metode borbe protiv stigme kako bi velikoj skupini ljudi osigurali osnovna ljudska prava. 


\section{Literatura}

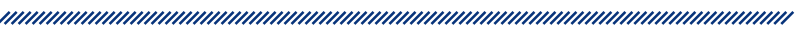

1. Pejović-Milovančević M, Lečić-Toševski D, Tenjović L, Popović-Deušić S, Draganić-Gajić. Changing attitudes of high school students towards peers with mental health problems. Psychiatria Danubina. 2009;21(2):213-219.

2. Frančišković T. Duševni poremećaji i stigma. U: Frančišković T, Moro Lj, ur. Psihijatrija. Zagreb: Medicinska naklada; 2009:254-457.

3. Frančišković $T$, Stevanović $A$, Blažić $D$, Petrić $D$, Šuković Z., Tovilović Z, Moro IN. Croatian war veterans in print media in 1996 and in 2006. Psychiatria Danubina. 2011;23(2):171-177.

4. Šendula Jengić V. Kriminogene specifičnosti psihotičnih počinitelja kaznenih dijela. Doktorska disertacija. Zagreb: Medicinski fakultet; 2008.

5. Crisp AH, Gelder MG, Rix S, Meltzer HI, Rowlands OJ. Stigmatisation of people with mental illnesses. British Journal of Psychiatry. 2000;177:4-7.

6. Filipčić I, Pavičić D, Filipčić A, Hotujac Lj, Begić D, Grubišin J, Đordević V. Attitudes of medical staff towards the psychiatric label „schizophrenic patient" tested by an anti-stigma questionare. Collegium Antropologicum. 2003;27(1):301-307.

7. Lai YM, Hong CP, Chee CY. Stigma of mental illness. Singapore Medical Journal. 2001;42:111-4.

8. Ertugrul A, Ulug B. Perception of stigma among patients with schizoprenia. Social Psychiatry and Psychiatric Epidemiology. 2004;39:73-7.

9. Wahl OF, Harman CR. Family views of stigma. Schizophrenia Bulletin. 1989;15:131-9.

10. Wahl OF. Mental health consumers experience of stigma. Schizophrenia Buletin. 1999;25:467-78.

11. Link BG, Phelan JC, Bresnahan M, Stueve A, Pescosolidu BA. Public conceptions of mental illness: labels, causes, dangerousness and social distance. Americal Journal of Public Health. 1999;89:1328-33.

12. Štrkalj Ivezić S, Jukić V, Hotujac Lj, Kušan Jukić M, Tikvica A. Organizacija zaštite mentalnog zdravlja u zajednici. Liječnički Vjesnik. 2010;132:38-42.

13. Jokić-Begić N, Kamenov Ž, Lauri Korajlija A. Kvalitativno i kvantitativno ispitivanje sadržaja stigme prema psihičkim bolesnicima. Socijalna psihijatrija. 2005;33(1):10-19.

14. Arbanas G. Adolescents' Attitudes toward schizophrenia, depression, and PTSD. Journal of Psychosocial Nursing. 2008;46(3):45-51.

15. Arbanas G. Stavovi maturanata medicinske škole prema shizofreniji, depresiji i posttraumatskom stresnom poremećaju. Socijalna psihijatrija. 2005;33(1):41-46.

16. Gallup Organization. Honesty/etics in professions. 2002.

17. Halter MJ. Stigma and help seeking related to depression: a study of nursing students. Journal of Psychosocial Nursing. 2004;42:42-51.
18. Caldwell TM, Jorm AF. Mental health nurses' beliefs about likely outcomes for people with schizophrenia or depression: a comparison with the public and other healthcare professionals. Australian and New Zealand Journal of Mental Health Nursing. 2001;10:42-54.

19. Lopez LR. Adolescents' attitudes toward mental illness and perceived sources of their attitudes and examination of pilot dana. Archives of Psychiatric Nursing. 1991;5:271-280. 


\section{DO NURSING STUDENTS STIGMATIZE PATIENTS SUFFERING FROM POSTTRAUMATIC STRESS DISORDER?}

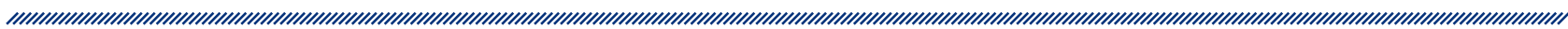

1 Josipa Rožman

1 Goran Arbanas

1 General hospital Karlovac, Department of Psychiatry, Andrije Štampara 3, 47000 Karlovac

\section{Abstract}

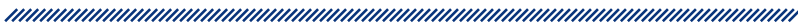

Psychiatric patients, in addition to the difficulties associated with their mental disorder, are faced with difficulties that arise from their stigmatization in the environment in which they live. Discriminating behaviours such as limits on health care, the right to education, various situations related to employment are just some of the examples that can further undermine their physical and psychological health. Stigma leads to low self-esteem and to feelings of isolation, loneliness and discrimination, which further complicates the treatment of the underlying disease.

Stigma often accompanies mental disorders and usually interferes with the treatment and patients' functioning. After the Homeland War in Croatia, there has been a high number of people suffering from posttraumatic stress disorder (PTSD). PTSD is often portrayed negatively in the media.

Participants were 94 nursing students. There were 85\% female participants with the average age of 32 (age range 22 to 54). Stigma toward schizophrenia, depression and PTSD was measured by a questionnaire with
15 items for each of the disorders, with Likert-type responses.

Nursing students showed much higher level of stigma toward schizophrenia, compared to PTSD and depression. Women were more stigmatizing toward schizophrenia than men. Freshmen students were more stigmatizing toward PTSD than sophomores and juniors. Older students (older than 36 ) were more stigmatizing, compared to younger students.

Keywords: stigma, schizophrenia, depression, PTSD, nursing students 